\title{
Bisphenol A measurement challenge
}

\section{Enea Pagliano ${ }^{1}$}

Accepted: 28 April 2021 / Published online: 5 July 2021

(C) Crown copyright in right of Canada 2021

We would like to invite you to participate in the Analytical Challenge, a series of puzzles to entertain and challenge our readers. This special feature of "Analytical and Bioanalytical Chemistry" has established itself as a truly unique quiz series, with a new scientific puzzle published every three months. Readers can access the complete collection of published problems with their solutions on the ABC homepage at http://www.springer.com/abc. Test your knowledge and tease your wits in diverse areas of analytical and bioanalytical chemistry by viewing this collection.

In the present challenge, Bisphenol $A$ is the topic. And please note that there is a prize to be won (a Springer book of your choice up to a value of $€ 100$,- given to one winner selected randomly). Please read on...

\section{Meet the challenge}

Prof. Phenole, a renowned analytical chemist, is engaging into a lectio magistralis on polycarbonate materials obtained from bisphenol A (BPA). Prof. Phenole pointed out that, since the 1950s, the demand of BPA and related compounds has witnessed an extensive growth. In fact, already in the 1980s, the worldwide production of BPA exceeded a million tons [1]. Prof. Phenole described the great mechanical and optical properties of polycarbonates and gave an overview of the risks related to these materials. She explained that food packaging, containers, and water bottles made of polycarbonates can leak BPA, and that this estrogen-like molecule can cause adverse health effects resulting in the disruption of the endocrine system [2].

Enea Pagliano

enea.pagliano@nrc-cnrc.gc.ca

1 National Research Council Canada, 1200 Montreal Road, K1A 0R6 Ottawa, Ontario, Canada
As a part of the analytical chemistry class, Prof. Phenole has tasked the students to think about a surveillance program to monitor the BPA levels in the tap water. The first assignment was the development of an accurate method for measuring BPA and top marks were promised to those who can propose a method with a relative standard uncertainty below $3 \%$.

The students accepted the challenge and began looking for suitable approaches. They quickly found an official method from the ISO standard collection [3]: the ISO 18857-2:2009 describes determination of BPA by GC-MS with isotopically labeled BPA- $d_{16}$ as an internal standard. The students were enthusiastic to use GC-MS for the first time, but were skeptical about the fully deuterated BPA$d_{16}$. Many scholars have noted that deuterated materials are not ideal internal standards [4-6]. For example, the properties of deuterated compounds can be quite different from the natural compounds which leads to differences in extraction yields [6]. A good demonstration of the different chemical behavior between the BPA and fully deuterated BPA can be seen from the GC-MS chromatogram of these two compounds-they can actually be resolved chromatographically [3]. In order to limit such unwanted isotopic effects, the students decided for a more robust ${ }^{13} \mathrm{C}$ labelled internal standard with a small number of carbon-13 atoms. For this purpose, they selected the NRC BPAL-1 Certified Reference Material [7] with five carbon-13 atoms (Fig. 1) as the internal standard.

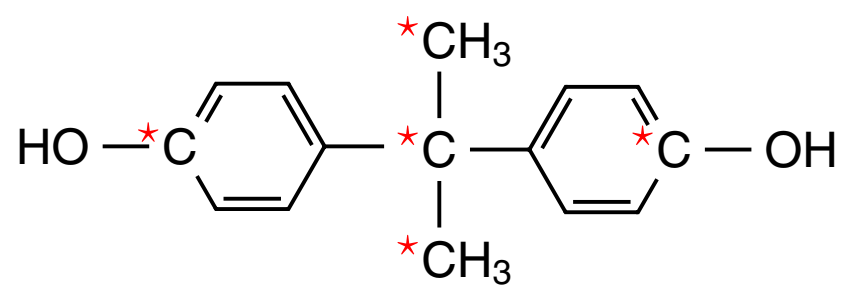

Fig. 1 NRC BPAL-1 CRM: the five ${ }^{13} \mathrm{C}$ labelled atoms are marked by red stars 
Although quantitation using isotopic standards (isotope dilution) is often explained with complicated mathematical formulae [8], all students voted to keep things simple and use a calibration curve $[9,10]$. Hence, a series of natural BPA standards $(0-500 \mathrm{ng} / \mathrm{g})$ was prepared gravimetrically. These standard solutions were then spiked with nearly equal amounts of the ${ }^{13} \mathrm{C}_{5}$-BPA internal isotopic standard and the resulting solutions were analyzed by GC-MS. The response curve (i.e., the measured isotope ratio vs the mass fraction of BPA) was obtained in Excel using the ordinary linear regression.

\section{The challenge}

The students set up the GC-MS acquisition method by following the experimental conditions found in the ISO 18857-2:2009. At this point, a series of BPA standards $(0-500 \mathrm{ng} / \mathrm{g})$ were prepared in acetone. The NRC BPAL1 standard was also prepared in acetone and used as internal standard $\left(94.4 \mathrm{ng} / \mathrm{g}{ }^{13} \mathrm{C}_{5}\right.$-BPA). The blends for calibration were prepared gravimetrically by mixing approx. $1.1 \mathrm{~mL}(0.86 \mathrm{~g})$ of natural BPA standards with approx. $0.5 \mathrm{~mL}(0.39 \mathrm{~g})$ of the internal standard. The blends were carefully mixed, and $25 \mu \mathrm{L}$ of $N$-methyl$N$-(trimethylsilyl)trifluoroacetamide (MSTFA, Fig. 2) was added to form the volatile trimethylsilyl derivative which was analyzed by GC-MS.

During the standard electron impact ionization, the trimethylsilyl derivative of the BPA produces an intense fragment at $[\mathrm{M}-15]^{+}$(loss of a methyl group). Therefore, signal acquisition was carried out in a selected ion monitoring mode by monitoring $\mathrm{m} / \mathrm{z} 357$ (the most abundant signal in the natural BPA) and $m / z, 361$ (the most abundant in the isotopically labelled internal standard). The isotope ratio in the analyzed BPA samples was calculated by dividing the chromatographic peak area at $m / z, 357$ with the peak at $m / z$ 361. All experimental data acquired by the students is reported in Table 1 and Fig. 3 shows the calibration curve along with the best linear fit. The students were proud of the calibration curve and the high value of their correlation coefficient $\left(R^{2}=0.9998\right)$. Things were looking very promising.

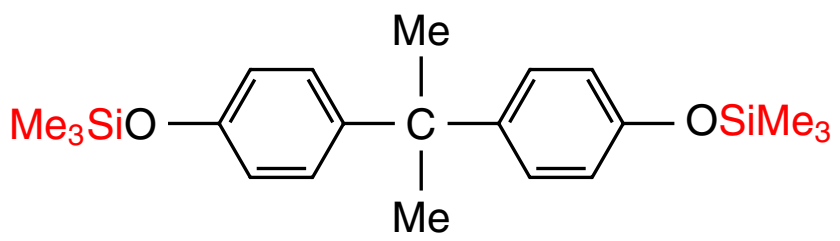

Fig. 2 BPA derivative after reaction with MSTFA
Table 1 Isotope dilution with ${ }^{13} \mathrm{C}_{5}$-BPA internal standard: calibration curve

\begin{tabular}{cllll}
\hline $\begin{array}{l}w_{\mathrm{A}} \\
\mathrm{ng} / \mathrm{g}\end{array}$ & $\begin{array}{l}m_{\mathrm{A}} \\
\mathrm{g}\end{array}$ & $\begin{array}{l}m_{\mathrm{B}} \\
\mathrm{g}\end{array}$ & $\begin{array}{l}w_{\mathrm{A}}\left(m_{\mathrm{A}} / m_{\mathrm{B}}\right) \\
\mathrm{ng} / \mathrm{g}\end{array}$ & $\begin{array}{l}r_{\mathrm{AB}} \\
\mathrm{V} / \mathrm{V}\end{array}$ \\
\hline 0.000 & 0.8867 & 0.3844 & 0.000 & $0.0149(23)$ \\
19.66 & 0.8693 & 0.3978 & 42.96 & $0.4338(42)$ \\
85.80 & 0.8835 & 0.3981 & 190.4 & $1.907(18)$ \\
126.7 & 0.8693 & 0.3965 & 277.8 & $2.753(32)$ \\
210.5 & 0.8789 & 0.3965 & 466.6 & $4.644(60)$ \\
304.5 & 0.8629 & 0.3963 & 663.0 & $6.592(75)$ \\
392.5 & 0.8662 & 0.3971 & 856.2 & $8.415(39)$ \\
477.4 & 0.8693 & 0.3948 & 1051 & $10.193(33)$ \\
\hline
\end{tabular}

The standard deviation of triplicate measurements (applicable to the last two digits of the value) is given in the parentheses

$w_{\mathrm{A}}$, mass fraction of natural $\mathrm{BPA} ; m_{\mathrm{A}}$, mass of the solution having $w_{\mathrm{A}}$ mass fraction; $m_{\mathrm{B}}$, mass of the internal standard solution having $w_{\mathrm{B}}=94.4 \mathrm{ng} / \mathrm{g} ; w_{\mathrm{A}}\left(m_{\mathrm{A}} / m_{\mathrm{B}}\right)$, corrected mass fraction $(x$-axis $) ; r_{\mathrm{AB}}$, measured isotope ratio of the blend (y-axis)

For quality control, the students tried to perform a calculation to verify if the equation obtained from the fitting was suitable to back-calculate the mass fraction of the calibration standards. For example, if $a_{0}$ and $a_{1}$ are intercept and slope of the calibration curve in Fig. 3, the concentration of the lowest standard could be calculated as follows:

$$
\begin{aligned}
w_{\mathrm{A}} & =\frac{m_{\mathrm{B}}}{m_{\mathrm{A}}} \cdot \frac{r_{\mathrm{AB}}-a_{0}}{a_{1}} \\
& =\frac{0.3978}{0.8693} \cdot \frac{0.4338-0.04856}{0.009742} \\
& =18.10 \mathrm{ng} / \mathrm{g}
\end{aligned}
$$

When the calculated BPA result for the lowest standard $(18.10 \mathrm{ng} / \mathrm{g}$, Eq. 1) was compared with the gravimetric preparation data $(19.66 \mathrm{ng} / \mathrm{g}$, Table 1$)$, a deviation of $-8.0 \%$ was found. Since the calibration curve looks so good, relative error on the $r_{\mathrm{AB}}$ was $<1 \%$ for data points above

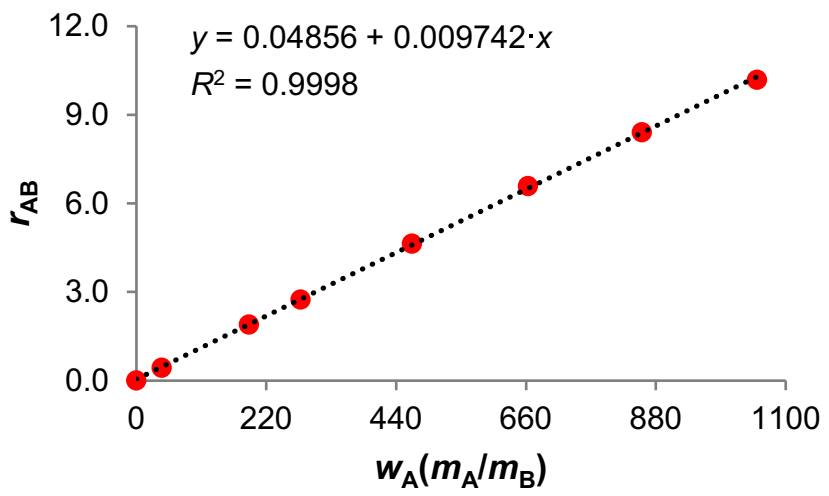

Fig. 3 Isotope dilution calibration curve of BPA with ${ }^{13} \mathrm{C}_{5}$-BPA internal standard 
blank, and the uncertainty on $w_{\mathrm{A}}\left(m_{\mathrm{A}} / m_{\mathrm{B}}\right)$ even smaller, students could not figure out why this standard shows such a big bias.

Is it too late for students to get top marks in the analytical chemistry class? Can you suggest a reason for this bias and provide a practical solution?

\section{Declarations}

Conflict of interests The author declares no competing interests.

\section{References}

1. Fiege $H$, Voges HW, Hamamoto $T$, Umemura $S$, Iwata $T$, Miki H, Fujita Y, Buysch HJ, Garbe D, Paulus W. Phenol derivatives. Ullmann's Encyclopedia of Industrial Chemistry. 2000. https://doi.org/10.1002/14356007.a19_313.

2. Rochester JR. Bisphenol A and human health: a review of the literature. Reprod Toxicol. 2013;42:132-55. https://doi.org/10.1016/j. reprotox.2013.08.008.

3. ISO 18857-2:2009. Water quality-determination of selected alkylphenols-part 2: gas chromatographic-mass spectrometric determination of alkylphenols, their ethoxylates and bisphenol A in non-filtered samples following solid-phase extraction and derivatisation.

4. Meija J, Mester Z. Paradigms in isotope dilution mass spectrometry for elemental speciation analysis. Anal Chim Acta. 2008;607(2):115-25. https://doi.org/10.1016/j.aca.2007.11.050.

5. González-Antuña A, Rodríguez-González $P$, Centineo $G$, García Alonso JI. Evaluation of minimal ${ }^{13} \mathrm{C}$-labelling for stable isotope dilution in organic analysis. Analyst. 2010;135:953-64. https://doi.org/10.1039/b924432h.
6. Itoh N, Numata M, Aoyagi Y, Yarita T. Comparison of the behavior of ${ }^{13} \mathrm{C}$ - and deuterium-labeled polycyclic aromatic hydrocarbons in analyses by isotope dilution mass spectrometry in combination with pressurized liquid extraction. J Chromatogr A. 2007;1138:26-31. https://doi.org/10.1016/j.chroma.2006.10.034.

7. Le PM, Bates J, Meija J, Pagliano E, Mester Z, Melanson J. BPAL-1: Certified Reference Material of [13C5]-bisphenol A. Ottawa: National Research Council Canada, Available from: https://doi.org/10.4224/crm.2017.bpal-1.

8. Pagliano E, Mester Z, Meija J. Reduction of measurement uncertainty by experimental design in high-order (double, triple, and quadruple) isotope dilution mass spectrometry: application to GC-MS measurement of bromide. Anal Bioanal Chem. 2013;405(9):2879-87. https://doi.org/10.1007/s00216-013-6724-5.

9. Pagliano E, Mester Z, Meija J. Calibration graphs in isotope dilution mass spectrometry. Anal Chim Acta. 2015;896:63-7. https://doi.org/10.1016/j.aca.2015.09.020.

10. Pagliano E, Meija J. A tool to evaluate nonlinearity in calibration curves involving isotopic internal standards in mass spectrometry. Int J Mass Spectrom. 2021;464:116557. https://doi.org/10.1016/ j.ijms.2021.116557.

We invite our readers to participate in the Analytical Challenge by solving the puzzle above. Please send the correct solution to abcchallenge@springer.com by October 1, 2021. Make sure you enter "Bisphenol A measurement challenge" in the subject line of your email. The winner will be notified by e-mail and their name will be published on the "Analytical and Bioanalytical Chemistry" homepage at http://www.springer.com/abc and in the journal (volume 414/issue 1) where readers will find the solution and a short explanation.

The next Analytical Challenge will be published in 413/24, October 2021. If you have enjoyed solving this Analytical Challenge you are invited to try the previous puzzles on the ABC homepage.

Publisher's note Springer Nature remains neutral with regard to jurisdictional claims in published maps and institutional affiliations. 